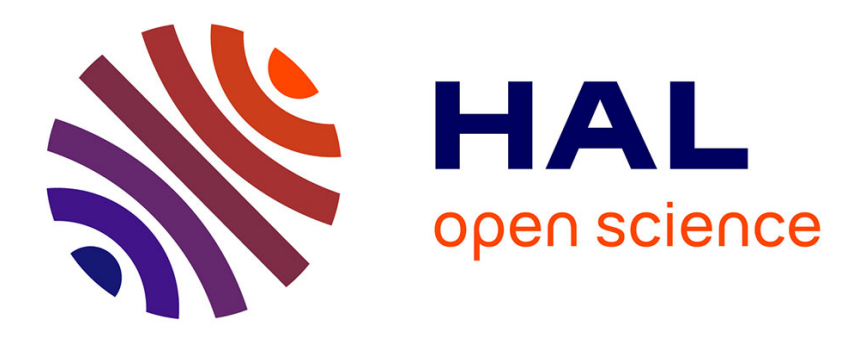

\title{
The empirical relevance of the competitive storage model
}

\author{
Carlo Cafiero, Eugenio S.A. Bobenrieth H., Juan R.A. Bobenrieth H., Brian \\ D. Wright
}

\section{- To cite this version:}

Carlo Cafiero, Eugenio S.A. Bobenrieth H., Juan R.A. Bobenrieth H., Brian D. Wright. The empirical relevance of the competitive storage model. Econometrics, 2009, 10.1016/j.jeconom.2009.10.008 . hal-00631675

\section{HAL Id: hal-00631675 \\ https://hal.science/hal-00631675}

Submitted on 13 Oct 2011

HAL is a multi-disciplinary open access archive for the deposit and dissemination of scientific research documents, whether they are published or not. The documents may come from teaching and research institutions in France or abroad, or from public or private research centers.
L'archive ouverte pluridisciplinaire HAL, est destinée au dépôt et à la diffusion de documents scientifiques de niveau recherche, publiés ou non, émanant des établissements d'enseignement et de recherche français ou étrangers, des laboratoires publics ou privés. 


\section{Accepted Manuscript}

The empirical relevance of the competitive storage model

Carlo Cafiero, Eugenio S.A. Bobenrieth H., Juan R.A. Bobenrieth H., Brian D. Wright

PII:

S0304-4076(09)00261-9

DOI: $\quad$ 10.1016/j.jeconom.2009.10.008

Reference: $\quad$ ECONOM 3261

To appear in: Journal of Econometrics

Please cite this article as: Cafiero, C., Bobenrieth H., E.S.A., Bobenrieth H., J.R.A., Wright, B.D., The empirical relevance of the competitive storage model. Journal of Econometrics (2009), doi:10.1016/j.jeconom.2009.10.008

This is a PDF file of an unedited manuscript that has been accepted for publication. As a service to our customers we are providing this early version of the manuscript. The manuscript will undergo copyediting, typesetting, and review of the resulting proof before it is published in its final form. Please note that during the production process errors may be discovered which could affect the content, and all legal disclaimers that apply to the journal pertain. 


\title{
The Empirical Relevance of the Competitive Storage Model ${ }^{1}$
}

\author{
Carlo Cafiero \\ Università degli Studi di Napoli Federico II, Italy \\ corresponding author: cafiero@unina.it
}

Eugenio S. A. Bobenrieth H.

Universidad de Concepción, Chile

Juan R. A. Bobenrieth H.

Universidad del Bío-Bío, Chile

Brian D. Wright

University of California at Berkeley, USA

draft: September 15, 2009

\begin{abstract}
The empirical relevance of models of competitive storage arbitrage in explaining commodity price behavior has been seriously challenged in a series of pathbreaking papers by Deaton and Laroque $(1992,1995,1996)$. Here we address their major criticism, that the model is in general unable to explain the degree of serial correlation observed in prices of twelve major commodities. First, we present a simple numerical version of their model which, contrary to Deaton and Laroque (1992), can generate the high levels of serial correlation observed in commodity prices, if it is parameterized to generate realistic levels of price variation. Then, after estimating the Deaton and Laroque $(1995,1996)$ model using their data set, model specification and econometric approach, we show that use of a much finer grid to approximate the equilibrium price function yields quite different estimates for most commodities. Results are obtained for coffee, copper, jute, maize, palm oil, sugar and tin that support the specifications of the storage model with positive constant marginal storage cost and no deterioration as in Gustafson (1958a). Consumption demand has low response to price and, except for sugar, there are infrequent stockouts. Observed magnitudes of serial correlation of price match those implied by the estimated model.
\end{abstract}

Subject headings: Autocorrelation, Commodity Prices, Pseudo Maximum Likelihood, Simulation, Storage.

\footnotetext{
${ }^{1}$ Work on this paper was supported by USDA CSREES National Research Initiative Grant No. 2005-35400-15978, Energy Biosciences Initiative, CONICYT/Fondo Nacional de Desarrollo Cientifico y Tecnologico (FONDECYT) Projects 1090017 and 1050562, Dirección de Investigación Universidad de Concepción and Dirección de Investigación Universidad del Bío-Bío. Wright is a member of the Giannini Foundation. We would like to thank two excellent anonymous referees for their advice, Elisabeth Sadoulet and Alain de Janvry for their support, and Betty Dow of the Development Prospects Group at the World Bank, for her help in providing the recent price data and resolving other data issues. We acknowledge the excellent assistance of Ernesto Guerra V.
} 


\section{Introduction}

Commodity price risk has long been an important concern for consumers and producers, and the potential of storage for moderating such risks is widely recognized. In 1958, Gustafson (1958a,b) made a major contribution to the study of the relation between storage and price risk when he presented his model of the market for a storable commodity subject to random supply disturbances, anticipating the concept of rational expectations of Muth (1961). Gustafson's model showed that competitive intertemporal storage arbitrage can smooth the effects of temporary gluts and, when stocks are available, temporary shortages. Subsequent numerical models in the Gustafson tradition, including Johnson and Sumner (1976), Gardner (1979), Newbery and Stiglitz (1981, Ch. 30) and Wright and Williams (1982) have confirmed that qualitative features of the price behavior of some important commodities are consistent with the effects of such arbitrage. In addition, numerical storage models (for example, Park 2006) can explain key qualitative features of peasants' economic behavior when they face high transaction costs, and the threat of hunger if local food crops fail and prices soar.

Estimation of theoretically acceptable models of price smoothing by storage arbitrage, however, was delayed for decades by absence of satisfactory time series of aggregate production and stocks for major commodities. Deaton and Laroque pioneered the empirical estimation of models of storage arbitrage, given such data limitations, by developing an estimation strategy that used only deflated price data, assuming a fixed interest rate and specifying the cost of storage as proportional deterioration of the stock. Their conclusions were discouraging regarding the contribution of storage models to our understanding of the nature of commodity price risk. They furnished a body of numerical and empirical evidence (Deaton and Laroque $1992,1995,1996)$ against the ability of their model to explain commodity price behavior, nicely summarized by Deaton and Laroque (2003, p. 290): "[T] he speculative model, although capable of introducing some autocorrelation into an otherwise i.i.d. process, appears to be incapable of generating the high degree of serial correlation of most commodity prices." Indeed they find the failure in this respect to be a general feature of the competitive storage model, rather than a question of whether their specifications could yield high correlations that are consistent with the data. (Deaton and Laroque 1995, p.S28)

In this paper we re-assess the relevance of speculative storage in explaining commodity price behavior. To do so, we must first address the claim that the inability to match high correlations observed in commodity price data is a general feature of the models, regardless of the parameterization. One set of evidence presented by Deaton and Laroque consists of simulations of various numerical specifications of the model (Deaton and Laroque 1992, p. 11) all of which fail to generate sufficiently high autocorrelation. We demonstrate that even their high variance simulation model with linear consumption demand, like key illustrative examples in Gustafson (1958a,b), Gardner (1979), and Williams and Wright (1991), fails to generate as much price variation as observed for the commodities they consider. With a less price-sensitive consumption demand curve, we show that storage can generate in their model levels of sample correlations and variation of price in the ranges observed for a number of major commodities. Thus the relevance of the storage model is re-established as an empirical question.

Our above numerical examples assume no storage cost apart from interest. It is clear that very high decay rates for stored commodities, such as those estimated by Deaton and Laroque $(1995,1996)$ (ranging from 6 to 18 percent per annum) would greatly reduce the correlations produced in our numerical examples, and make it less likely that storage would in fact induce the high correlations observed in price. A brief review of information on storage costs for some commodities and time periods yields no cases consistent with such high decay rates. Indeed the evidence in general points to a specification presented in Gustafson 
(1958a), with positive constant marginal storage cost.

Using the econometric approach of Deaton and Laroque $(1995,1996)$ and the same thirteen commodity price dataset, ${ }^{2}$ we move on to estimation. First, we re-evaluate the empirical results of the PML estimates of Deaton and Laroque $(1995,1996)$ for the case of i.i.d. production. Using a model based on our understanding of their empirical model and its implementation, we replicate the results for most commodities quite accurately, including the very high decay rates estimated by Deaton and Laroque.

However, investigation of their estimation procedure reveals their fit of the price function to be unsatisfactory, due to use of insufficient grid points in approximating the price functions through splines. Reestimation with finer grids yields quite different estimates, with the estimated decay cost of storage reduced or eliminated when the number of grid points is substantially increased, for most commodities. Simulations based on the models estimated with the finer grids reveal that for five commodities: coffee, copper, maize, palm oil and sugar, the observed value of first order correlation of prices lies within their symmetric ninety percent confidence regions.

We then estimate a model that allows for a fixed positive marginal cost of storage, as well as for the possibility of positive deterioration of stocks, which therefore nests the model of Deaton and Laroque $(1995,1996)$. We obtain results for seven commodities, coffee, copper, jute, maize, palm oil, sugar, and tin. Estimates indicate a fixed positive marginal storage cost with no deterioration, providing empirical support to the specification used in Gustafson (1958a). Simulations based on each of our estimates using this specification produce sample distributions of the first and second order autocorrelation that include observed values within the ninety percent symmetric confidence regions. Estimation using the alternate two percent real interest rate assumed by Gustafson (1958a) shows even better matches of mean prices, predicted autocorrelations, and coefficients of variation with the observed data.

Thus we have established that competitive storage can generate the high levels of autocorrelation observed for the prices of major commodities. Further, application of Deaton and Laroque's econometric approach, modified to improve its numerical accuracy, using their own data set, can yield empirical results that are consistent with observed levels of price variation and autocorrelation for seven major commodities.

\section{Can storage generate high serial correlation?}

We begin by focusing on a preliminary question: can a simple storage model with i.i.d. production disturbances generate price autocorrelations that are similar to those observed in time series for major commodities? To address this question, we consider specifications of the storage model that are special cases of models presented in Gustafson (1958a), and Deaton and Laroque (1992).

Production is given by an i.i.d. sequence $\omega_{t}(t \geq 1)$ with bounded support. Available supply at time $t$ is $z_{t} \equiv \omega_{t}+x_{t-1}$, where $x_{t-1} \geq 0$ are stocks carried from time $t-1$ to time $t$. Consumption $c_{t}$ is the difference between available supply $z_{t}$ and stocks $x_{t}$ carried forward to the next period. The inverse consumption demand $F(c)$ is strictly decreasing. There is no storage cost apart from an interest rate $r>0$. Storage and

\footnotetext{
${ }^{2}$ The commodities are bananas, cocoa, coffee, copper, cotton, jute, maize, palm oil, rice, sugar, tea, tin and wheat. The original price indexes, attributed to World Bank sources, and a series for the United States Consumer Price Index, are available on-line at http://qed.econ.queensu.ca/jae/1995-v10.S/deaton-laroque/. The data reported as the US CPI for the period 19001913 appear to be from the deflator presented in Rees (1961).
} 
price satisfy the arbitrage conditions:

$$
\begin{aligned}
& x_{t}=0, \quad \text { if }(1+r)^{-1} E_{t} p_{t+1}<p_{t}, \\
& x_{t} \geq 0, \quad \text { if }(1+r)^{-1} E_{t} p_{t+1}=p_{t},
\end{aligned}
$$

where $p_{t}$ represents the price at time $t$, and $E_{t}$ is the expectation conditional on information at time $t$. The above complementary inequalities are consistent with profit-maximizing speculation by risk-neutral price-takers.

To investigate whether there exist, within the parameter space of the model, specifications that yield price behavior characteristic of observed commodity markets, one can solve the model for each of a set of parameterizations by numerical approximation of the equilibrium price function, and then derive by numerical methods the implications for time series of price behavior. In the numerical approximations of Deaton and Laroque (1992, Table 2, p. 11), the highest autocorrelation of price that they report is produced by a specification that they denote the "high-variance case", which matches an example in Williams and Wright (1991, pp. 59-60), with no deterioration or other physical storage cost, $r=0.05$, linear inverse consumption demand, $F(c)=600-5 c$, and production realizations drawn from a discrete approximation to the normal distribution (with mean 100 and standard deviation 10). This case implies a price autocorrelation of 0.48 , far below the sample correlations calculated from the 88-year time series of prices of thirteen commodities (bananas, cocoa, coffee, copper, cotton, jute, maize, palm oil, rice, sugar, tea, tin, and wheat as listed in Table 1) which are all in excess of 0.62 . They conclude that perhaps the autocorrelation observed in commodity prices needs to be explained by phenomena other than storage (Deaton and Laroque 1992, page $19)$.

Our solution of the storage model for the same specification, when simulated 100, 000 periods, yields first and second order autocorrelations of prices, over this long sample, of 0.47 and 0.31 . These values are close to those obtained by Deaton and Laroque (1992) for the invariant distribution (0.48 and 0.31, respectively).

In order to assess the implications of the model for samples of the same length as those of the observed commodity price series used for this paper, we take successive samples of size 88 from the simulated series, the first starting from period $t=1$, the second from period $t=2$, and so on, and measure autocorrelation and coefficient of variation for each of them. Figure 1 shows histograms of simulated sample first order correlations and coefficients of variation for this exercise. The median of the first order autocorrelations is 0.45 . The 90 -th percentile is 0.61 , a little below the lowest value in the commodity price series, which is 0.62 , for sugar. For all twelve others in Table 1, the values are above 0.7 , the 98.5 percentile of the distribution of simulated values; it is clear that the example does not match the data for these others at all well. The same criticism applies to many of the other examples in Wright and Williams (1982), and Williams and Wright (1991), with similar specifications.

However this "high-variance case" has another problem. It does not generate sufficient price variation to match the values for most of the commodities in the 88-year samples. The long run estimate of the coefficient of variation of price is 0.25 , half its value when storage is not possible.

The coefficients of variation for the time series of prices of all the commodities in Table 1 but bananas and tea lie above the 98th percentile of the distribution of sample values generated from simulation of this numerical model. It is clear that this specification, and the others considered in Gustafson (1958a,b), Gardner (1979), Wright and Williams (1982), Williams and Wright (1991) and Deaton and Laroque (1992, Table 2, p. 11), in fact imply lower price variation than observed in major commodity markets. Although it is conceivable that variation in production has been substantially underestimated, it appears more likely that 
the consumption demand functions specified in the numerical models, with price elasticities (at consumption equal to mean production) in the range -0.5 to -0.1 , are more sensitive to price than are consumption demands in the markets we consider. ${ }^{3}$ Hence the simulations exhibit too little storage, too many stockouts, and consequently values for price variation and serial correlation that are too low to match those observed in the time series of prices of major commodities.

To increase the price variation in the model, we rotate the linear consumption demand around its mean, changing its price elasticity at that point from -0.2 to -0.067 , not, a priori, an unreasonable value for the demand for a basic commodity. Once again we solve the model and generate a simulated sample of 100,000 periods. The results are presented in Figure 2.

The median of the sample coefficients of variation derived from this numerical exercise is 0.46 , quite close to the observed values for many of the commodities. Only bananas and tea have values less than the fifth percentile of the generated sample distribution. The median of the distribution of sample first-order correlations generated by simulation is 0.60 . The values for 6 commodities, coffee, jute, maize, palm oil, sugar, and tea lie between 5 -th and the 95-th percentiles.

Figures 1 and 2 together show that tripling the price variation that would occur without storage leads to sufficiently greater arbitrage that the median price variation only doubles. The greater arbitrage is also reflected in much higher serial correlation.

The simulations discussed above favor storage and high serial correlation by assuming no storage cost other than interest charges. But physical storage costs are not in general zero. Before moving to a discussion of estimation of the model, we discuss the choice of storage cost specification for the estimated model.

\section{The cost of storage}

Gustafson (1958a,b) and much of the subsequent literature (including Johnson and Sumner 1976; Newbery and Stiglitz 1979, chapter 29; Wright and Williams 1982; Miranda and Helmberger 1988 and Williams and Wright 1991) focus on models where the marginal physical cost of storage is constant. In contrast, Samuelson (1971) and Deaton and Laroque $(1992,1995,1996)$ specify storage cost as constant proportional deterioration or shrinkage of the stock. This implies that, since price is decreasing in stocks, the marginal cost of storage is high when stocks are low.

The fees for storage in public warehouses might be considered to be upper bounds on annual storage costs. They furnish some evidence regarding the choice between these cost specifications. When a commodity such as a grain or a metal is deposited in a warehouse, the warehouse receipt specifies the grade and quantity, and the depositor receives the right to withdraw later an equal quantity of the same grade. Any shrinkage or other deterioration is implicitly covered in the storage fee. There is evidence for some commodities that, within the sample period, the fee for storing one unit of commodity per unit of time has remained constant and independent of price movements over substantial time intervals. ${ }^{4}$ This suggests that the cost

\footnotetext{
${ }^{3}$ Choice of the appropriate demand elasticity is a challenge, due to the difficulty in empirically distinguishing consumption and storage demand responses. This problem is noted by Gardner (1979) in his discussion of the finding of Hillman, Johnson and Gray (1975) that wheat demand elasticity is smaller at higher prices.

${ }^{4}$ For example Holbrook Working reports that daily charges for wheat storage in public elevators in Chicago were constant from December 1910 through December 1916 (Working 1929, p. 22). A detailed analysis of the cost of storing a number of major commodities around the decade of the 1970s, when prices were highly volatile, is found in UNCTAD (1975). The
} 
of deterioration, which is proportional to value, might be too small to justify price-contingent storage fees. To allow for this possibility, in our empirical model we specify the cost of storage to include both a fixed marginal physical cost and non-negative deterioration. ${ }^{5}$

\section{The model and the estimation procedure}

We model a competitive commodity market with constant, strictly positive marginal and average storage cost and proportional deterioration. All agents have rational expectations.

Supply shocks $\omega_{t}$ are i.i.d., with support in $\mathbb{R}$ that has lower bound $\underline{\omega} \in \mathbb{R}$. Storers are risk neutral and have a constant discount rate $r>0$. Stocks physically deteriorate at rate $d$, with $0 \leq d<1$, and the cost of storing $x_{t} \geq 0$ units from time $t$ to time $t+1$, paid at time $t$, is given by $k x_{t}$, with $k>0$. The state variable $z_{t}$ is total available supply at time $t, z_{t} \equiv \omega_{t}+(1-d) x_{t-1}$, with $z_{t} \in Z \equiv[\underline{\omega}, \infty[$. Inverse consumption demand, $F: \mathbb{R} \rightarrow \mathbb{R}$, is continuous, strictly decreasing, with $\{z: F(z)=0\} \neq \emptyset, \lim _{z \rightarrow-\infty} F(z)=\infty$, and $\left(\frac{1-d}{1+r}\right) E F\left(\omega_{t}\right)-k>0$, where $E$ denotes the expectation taken with respect to the random variable $\omega_{t}$.

A stationary rational expectations equilibrium, (SREE), is a price function $p: Z \rightarrow \mathbb{R}$ which describes the current price $p_{t}$ as a function of the state $z_{t}$, and satisfies for all $z_{t}$,

$$
p_{t}=p\left(z_{t}\right)=\max \left\{\left(\frac{1-d}{1+r}\right) E_{t} p\left(\omega_{t+1}+(1-d) x_{t}\right)-k, F\left(z_{t}\right)\right\}
$$

where:

$$
x_{t}=z_{t}-F^{-1}\left(p\left(z_{t}\right)\right) .
$$

Since the $\omega_{t}$ 's are i.i.d., $p$ is the solution to the functional equation

$$
p(z)=\max \left\{\left(\frac{1-d}{1+r}\right) \operatorname{Ep}(\omega+(1-d) x(z))-k, F(z)\right\},
$$

and

$$
x(z)=z-F^{-1}(p(z)) .
$$

Existence and uniqueness of the SREE, as well as some properties are given by the following Theorem:

Theorem. There is a unique stationary rational expectations equilibrium $p$ in the class of continuous nonincreasing functions. Furthermore, for $p^{*} \equiv\left(\frac{1-d}{1+r}\right) E p(\omega)-k$,

$$
\begin{aligned}
& p(z)=F(z), \quad \text { for } \quad z \leq F^{-1}\left(p^{*}\right), \\
& p(z)>F(z), \quad \text { for } \quad F^{-1}\left(p^{*}\right)<z .
\end{aligned}
$$

reported costs are not presented as contingent on the commodity prices. Where relevant, costs of rotation of stocks to prevent deterioration are explicitly recognized. Williams (1986, pp. 213-214) reports that for cocoa, which spoils more easily than major grains, warehouse storage fees in New York stayed around \$5 per ton per month from 1975 through 1984 while the cocoa price fluctuated wildly, between $\$ 1,063$ and $\$ 4,222$ per ton. In Oklahoma, Texas, Arkansas and Kansas, public elevators charge the same fees per bushel for several grains, and these fees, which implicitly cover any shrinkage or deterioration, remain constant for considerable periods of time. For example, in Oklahoma, grain storage costs per bushel was 2.5 cents per month from 1985 through 2000 (Anderson 2005).

${ }^{5}$ Like Deaton and Laroque $(1992,1995,1996)$, we ignore the cost of initially placing the commodity in a warehouse, and the cost of withdrawal. Implications of costs of withdrawal for commodity prices are explored in Bobenrieth, Bobenrieth, and Wright (2004). 
$p$ is strictly decreasing. The equilibrium level of inventories, $x(z)$, is strictly increasing for $z>F^{-1}\left(p^{*}\right)$.

Our proof of this Theorem follows the same structure as the proof of Theorem 1 in Deaton and Laroque $(1992){ }^{6}$

We estimate the model described in this section assuming the inverse consumption demand is $F(c)=$ $a+b c$, where $c$ is consumption, using the pseudo-likelihood maximization procedure of Deaton and Laroque $(1995,1996){ }^{7}$ First, we choose values $\omega_{t+1}^{n}$ and $\operatorname{Pr}\left(\omega_{t+1}^{n}\right)$ to discretize the standard normal distribution, ${ }^{8}$ so that condition (1) can be expressed as:

$$
p_{t}=p\left(z_{t}\right)=\max \left\{\left(\frac{1-d}{1+r}\right) \sum_{n=1}^{N} p\left(\omega_{t+1}^{n}+(1-d) x_{t}\right) \operatorname{Pr}\left(\omega_{t+1}^{n}\right)-k, a+b z_{t}\right\} .
$$

Next, we solve (3) numerically by approximating the function $p$ with cubic splines on a grid of points over a suitable range of values of $z_{t}$, imposing the restriction represented by (2).

Then, using the approximate SREE price function $p$, we calculate the first two moments of $p_{t+1}$ conditional on $p_{t}$ :

$$
\begin{gathered}
m\left(p_{t}\right)=\sum_{n=1}^{N} p\left(\omega_{t+1}^{n}+(1-d)\left(p^{-1}\left(p_{t}\right)-F^{-1}\left(p_{t}\right)\right)\right) \operatorname{Pr}\left(\omega_{t+1}^{n}\right), \\
s\left(p_{t}\right)=\sum_{n=1}^{N} p\left(\omega_{t+1}^{n}+(1-d)\left(p^{-1}\left(p_{t}\right)-F^{-1}\left(p_{t}\right)\right)\right)^{2} \operatorname{Pr}\left(\omega_{t+1}^{n}\right)-m^{2}\left(p_{t}\right) .
\end{gathered}
$$

To match the prediction of the model with the actual price data, we form the logarithm of the pseudolikelihood function as:

$$
\ln L=\sum_{t=1}^{T-1} \ln l_{t}=0.5\left(-(T-1) \ln (2 \pi)-\sum_{t=1}^{T-1} \ln s\left(p_{t}\right)-\sum_{t=1}^{T-1} \frac{\left(p_{t+1}-m\left(p_{t}\right)\right)^{2}}{s\left(p_{t}\right)}\right)
$$

Keeping the interest rate fixed, we maximize the log pseudo-likelihood function (4) with respect to the vector of parameters $\tilde{\theta} \equiv\{a, \tilde{b}, \tilde{d}, \tilde{k}\}$ where $b=-e^{\tilde{b}}, d=e^{\tilde{d}}$, and $k=e^{\tilde{k}}$. The transformation is used to impose the restrictions $b<0, d>0$, and $k>0$. Even though (4) is not the true log-likelihood (in presence of storage, prices will not be distributed normally), the estimates are consistent (Gourieraux, Monfort, and Trognon 1984).

To estimate the variance-covariance matrix of the vector of original parameters $\theta \equiv\{a, b, d, k\}$, we first obtain a consistent estimate of the variance-covariance matrix of the parameters $\tilde{\theta}$ by forming the following

\footnotetext{
${ }^{6}$ When there is a constant additive positive marginal storage cost, equilibrium price realizations can be negative. Recognition of free disposal avoids this problem. A proof of a version of the Theorem for a model with positive marginal storage cost, possibly unbounded realized production, and free disposal is available from the authors.

${ }^{7}$ We are grateful to Angus Deaton for sending us their estimation code. Based on this generous assistance, we developed our MATLAB code drawing on our interpretation of the original code, which was, quite understandably, not documented for third-party use. We added code for estimation of standard errors.

${ }^{8}$ In practice, as in Deaton and Laroque $(1995,1996), \omega_{t+1}^{n}$ is restricted to take one of the conditional means of $N=10$ equiprobable intervals of the standard normal distribution, $\pm 1.755, \pm 1.045, \pm 0.677, \pm 0.386, \pm 0.126$. The restrictions of zero mean and unit variance for the distribution of the supply shocks are imposed to identify the model (see Deaton and Laroque 1996, Proposition 1, p. 906).
} 
expression:

$$
\tilde{\mathbf{V}}=\mathbf{J}^{-1} \mathbf{G}^{\prime} \mathbf{G} \mathbf{J}^{-1},
$$

where the matrices $\mathbf{J}$ and $\mathbf{G}$ have typical elements:

$$
J_{i, j}=\frac{\partial^{2} \ln L}{\partial \tilde{\theta}_{i} \partial \tilde{\theta}_{j}} \quad \text { and } \quad G_{t, i}=\frac{\partial \ln l_{t}}{\partial \tilde{\theta}_{i}} ;
$$

calculated by taking numerical derivatives ${ }^{9}$ of the $\log$-pseudo likelihood, $\ln L$, and of its components, $\ln l_{t}$, all evaluated at the point estimates of the parameters $\tilde{\theta}$ (see Deaton and Laroque 1996, equation 18).

A consistent estimate of the variance covariance matrix of the original parameters $\theta$ is obtained using the delta method, as:

$$
\mathbf{V}=\tilde{\mathbf{D}} \tilde{\mathbf{V}} \tilde{\mathbf{D}}^{\prime}
$$

where $\tilde{\mathbf{D}}$ is a diagonal matrix of the derivatives of the transformation functions:

$$
\tilde{\mathbf{D}}=\left\{\begin{array}{llll}
1 & 0 & 0 & 0 \\
0 & -e^{\tilde{b}} & 0 & 0 \\
0 & 0 & e^{\tilde{d}} & 0 \\
0 & 0 & 0 & e^{\tilde{k}}
\end{array}\right\}
$$

\section{Data and empirical results}

Our initial data set, which is identical to that reported by Deaton and Laroque (1995), consists of a widely used set of commodity price indices, deflated by the United States Consumer Price Index, for bananas, cocoa, coffee, copper, cotton, jute, maize, palm oil, rice, sugar, tea, tin, and wheat for the period 1900-1987, with features summarized in Table $1 .{ }^{10}$

\subsection{Replication of the PML results of Deaton and Laroque}

To check our estimation routine, we first estimate the model with $k=0$, adopting parameterizations and grid specifications of Deaton and Laroque $(1995,1996)$ assuming the same interest rate, five percent. As shown in Table 2, we essentially replicate the point estimates of the parameters for ten of the thirteen commodities. Like Deaton and Laroque, we were unable to obtain an estimate for bananas, and do not consider this commodity further. For other two commodities, maize and wheat, our estimates have higher pseudo likelihood values, and lower estimates of the rate of deterioration.

\subsection{Estimation of the constant-decay model with a finer grid}

In considering the estimation procedure, we have been concerned that the use of cubic splines to approximate the function $p$ in the region of zero inventories might induce non-negligible errors if the grid is sparse,

\footnotetext{
${ }^{9}$ All numerical derivatives are obtained with a Matlab routine coded following Miranda and Fackler (2002, pp. 97-104).

${ }^{10}$ For sources of these data see footnote 2 .
} 
due to the fact that $p$ is kinked (see Michaelides and Ng 2000, p. 243, and Cafiero 2002). ${ }^{11}$ To investigate the extent of the approximation error, we first solve the numerical model with the grid sizes and limits used by Deaton and Laroque (1995), and then with a much finer grid of one thousand points with the same limits. In both numerical exercises we assume linear inverse consumption demand, $F(c)=a+b c$, with parameters $a=0.645, b=-0.624$, and decay rate $d=0.179 .^{12}$ Figure 3 shows the effect of the change in grid size on the accuracy of approximation of the price function.

Notice that the fine grid of one thousand points allows for clear identification of the kink in the price function, which occurs at a price equal to $p^{*}$, and that the inaccuracy of the approximation of the price function with a sparse grid is especially large around that point, within a range where many prices are observed. This affects the accuracy of the evaluation of the pseudo likelihood function, which makes use of the approximated price function to map from the observed price to the implied availability (see for example equations 41 and 43 in Deaton and Laroque, 1995). ${ }^{13}$

To assess the extent of the effect induced by the approximation error on the estimation, we experiment by estimating the model for various numbers of grid points, on the presumption that a finer grid would reduce the errors associated with the spline approximation of the price function. The results of this experiment are reported in Table 3 for cotton and sugar. The estimates appear to become robust to the number of grid points only when the grid is sufficiently fine; one thousand grid points appears to be adequate.

Using one thousand grid points, we are unable to obtain estimates for rice, tin and wheat, while for sugar we identify two maxima of the pseudo likelihood (we report the maximum with the higher pseudo-likelihood value). For the other commodities, we find only one well-behaved maximum of the pseudo likelihood. Increasing the number of grid points to one thousand decreases the point estimate of the depreciation rate substantially, for every commodity with the exception of tea (see Table 4).

The effects of use of a finer grid for function approximation on the estimation results are illustrated in Figure 4, taking sugar as an example. With the finer grid, the model estimates a substantially steeper consumption demand (the slope of the inverse demand function changes from -0.6249 to -1.2661 ) and the estimated cutoff value $p^{*}$ increases from 0.6199 ( $87.3 \%$ of the mean price, located close to the 52 nd percentile of the observed price distribution) to 0.9018 ( $127.1 \%$ of the mean price, located at the 74 th percentile), that is by an amount that is large relative to the distribution of observed prices. These changes in the estimated values imply much more storage (the average amount of stocks held over a long simulated series of 100,000 periods increases from 0.44 , as predicted by the parameters estimated with the sparse grid, to 4.17 , as predicted instead with the parameters obtained with the fine grid) and much higher price autocorrelations than reported in Deaton and Laroque $(1995,1996)$ : the model estimated with the 1000 grid points implies a first order autocorrelation of 0.647 in a simulation of 100,000 periods, as opposed to the values of 0.264 , as reported by Deaton and Laroque (1996, Table I) and of 0.223 , as implied by our replication of the Deaton

\footnotetext{
${ }^{11}$ Deaton and Laroque use spline smoothing, to obtain faster convergence of their numerical algorithm. See for example Deaton and Laroque (1995, p. S26).

${ }^{12}$ These are the values obtained in our replication of the estimates of Deaton and Laroque for sugar, reported in Table 2 below.

${ }^{13}$ For prices above the kink point, the implied levels of stock, i.e. the difference between implied availability and consumption, should be zero. Use of the smoother function in Figure 3 would predict negative stocks. The effect of this appears to be reflected in Figure 7 and in the dotted line of Figure 9 of Deaton and Laroque (1995), which represents the predictions from their estimation of the i.i.d. storage model. Such prediction should coincide with $p^{*}(1+r) /(1-d)$ whenever current price is above $p^{*}$.
} 
and Laroque model reported in Table 2.

\subsection{Estimation of the model with constant marginal storage cost}

In this section, we set the number of grid points at 1000 and estimate the model allowing for a positive $k$, assuming initially an interest of five percent, as in Deaton and Laroque $(1995,1996)$ and Gustafson $(1958 \mathrm{a})$. The lowest value of the range of $z$ over which the price function is approximated is lower than the lowest possible production. The upper bound of the range for approximation should be large enough to ensure that the approximated function would cover even the lowest price data point. Finding this required some experimentation for the various commodities, with results reported in Table 5 .

Estimating the model presented in section 4, we find maxima for the pseudo likelihood function for seven commodities, coffee, copper, jute, maize, palm oil, sugar and tin. We are unable to locate well behaved maxima for cocoa, cotton, rice, tea and wheat.

For each of the seven commodities for which we obtain estimates, the estimated value of $d$ approaches zero, ${ }^{14}$ while $k$ is estimated to be strictly positive. Results given $d=0$ are presented in Table 6 . The log pseudo likelihood values for our estimated models are all higher than the corresponding values reported by Deaton and Laroque $(1995,1996)$ for their storage model with i.i.d. shocks and proportional deterioration (see Table 8). They are also substantially higher than the log likelihood values reported for the AR(1) model by Deaton and Laroque $(1995,1996)$ and reproduced in Table 8 . Table 7 shows estimates of the constant marginal storage cost model using Gustafson's alternate interest rate of two percent. Other than for sugar, these latter had the highest maximized pseudo likelihood values.

\subsection{Empirical distributions of implied time series characteristics}

To explore the characteristics of time series of prices implied by the econometric results, we simulate all of the estimated models to generate price series of 100,000 periods. ${ }^{15}$

Table 9 shows the values of mean price, first order correlation, second order correlation, and coefficient of variation measured on the observed prices, 1900-1987. These values are then located within the empirical distributions of the same parameters generated from all possible samples of 88 consecutive periods drawn from each series of 100,000 prices. The table reports the corresponding percentiles.

Our replication of the estimates of Deaton and Laroque $(1995,1996)$, identified in Table 9 as "proportional decay, sparse grid" with the caveats noted in Table 2, imply much too little price autocorrelation, consistent with their conclusions, for all commodities but maize. For maize, our estimation results (which differ from those of Deaton and Laroque) appear to imply sample distributions quite consistent with the observed mean, correlations, and coefficient of variation of maize price indexes.

With the finer grid, estimates of the same model imply symmetric $90 \%$ confidence intervals for coffee,

\footnotetext{
${ }^{14}$ We estimate $\tilde{d}=\log (d)$, which tends to large negative numbers as $d$ approaches zero. At some point, the slope of the objective function with respect to $\tilde{d}$ falls below the preset tolerance. When this occurs, we set $d=0$ and re-run the estimations.

${ }^{15}$ In all the simulations, we use a series of 100,000 independent draws from a normal distribution with mean zero and variance one, truncated at \pm 5 standard deviations.
} 
copper, maize, palm oil and sugar which contain the observed values. Though the estimates for all of these commodities except palm oil present other problems, they cannot support rejection of the storage model for failure to reproduce observed levels of price autocorrelation.

Estimation of the constant marginal storage cost model with the 1000-point grid and, as above, a five percent interest rate, implies that observed first and second order correlations lie within symmetric ninety percent confidence regions for seven commodities, coffee, copper, jute, maize, palm oil, sugar and tin, as shown in Table 9. In this sense, the speculative storage model is consistent with observed autocorrelation of the prices of these commodities.

However, for jute and coffee the empirical ninety percent symmetric confidence regions do not contain the observed coefficient of variation of price. For four of the seven commodities, the observed mean price lies below its confidence interval. For jute in particular, our estimation of the Gustafson specification of the speculative model implies too much price variation, rather than too little correlation.

Finally, simulation of the models estimated assuming Gustafson's alternate two percent interest rate provided the best match, for each commodity, of estimated mean price, serial correlations, and coefficient of variation with the observed data.

A feature of the results is that, according to the estimated models, stockouts occurred over the sample interval only for sugar. For other commodities, the cutoff price for storage, $p^{*}$, exceeds the highest price observed between 1900 and 1987. For all commodities but sugar, Table 10 shows that the probability of at least one stockout, in an 88-period sample drawn from the simulated series of 100,000 observations, is less than 0.88 at $r=0.05$, and less than 0.63 at $r=0.02$.

A stringent check on our results is to calculate the realized profits for a speculator who buys one unit of the commodity when the price is below $p^{*}$, and resells the unit in the next period. For the observed time series for each commodity, we compare the realized profits from such strategy with the simulated sample distributions of profits for the 88-period sequences. Percentiles for realized average profits are presented in Table 11. For all 7 commodities, imputed profits lie within each corresponding $90 \%$ symmetric confidence interval.

\section{Conclusion}

Our numerical and empirical results offer a new, more positive assessment of the empirical relevance of the commodity storage model. The pathbreaking and influential work of Deaton and Laroque includes an empirical implementation that exhibits problems of accuracy of approximation, which we show lead to substantial errors in estimation of the consumption demand functions and decay rates. When a finer grid is used, Deaton and Laroque's model yields estimates that are consistent with observed levels of price autocorrelation, for five commodities.

Our estimates of the model that allows also for constant marginal storage cost in addition to proportional deterioration imply distributions of sample autocorrelations that generate ninety percent confidence intervals that include observed values for seven major commodities, coffee, copper, jute, maize, palm oil, sugar, and tin. The estimates imply constant marginal storage cost with no significant deterioration and lower price elasticities of consumption demand than assumed in most numerical storage models. Though no stockouts are indicated, except for sugar, over the 1900-1987 period, average speculative profits implied by the model for those years are well within reasonable confidence regions for samples of that size. 
The empirical results suggest that numerical models in the tradition of Gustafson have tended to assume price sensitivity of consumption demand (as distinct from market demand) higher, and price variability lower, than indicated for the seven commodities we consider. With less flexibility of consumption than previously assumed, storage arbitrage is more active, and stockouts are less frequent, inducing the high levels of serial correlation observed in the prices of these commodities. Note that the implications of such price behavior for producer risk management are not straightforward. Short run price variation is in general lower, but price slumps are more persistent, than in an equivalent market with the lower levels of price autocorrelation indicated in previous empirical estimates. These results open the way for further empirical exploration of the role of commodity storage in reducing the amplitude, and increasing the persistence, of price variation encountered in commodity markets.

\section{REFERENCES}

Anderson, K. (2005): Personal communication, Agricultural Extension Service. Oklahoma State University.

Bobenrieth, E. S. A., J. R. A. Bobenrieth, and B. D. Wright (2004): "A Model of Supply of Storage," Economic Development and Cultural Change, 52, 605-616.

Cafiero, C. (2002): "Estimation of the Commodity Storage Model," unpublished Ph.D. Dissertation, Department of Agricultural and Resource Economics, The University of California at Berkeley.

Campbell, J. (1999): "Asset Prices, Consumption and the Business Cycle," in Handbook of Macroeconomics, ed. by J. Taylor, and M. Woodford, chap. 19. North-Holland, Amsterdam.

Deaton, A., and G. Laroque (1992): "On the Behaviour of Commodity Prices," Review of Economic Studies, $59(1), 1-23$.

(1995): "Estimating a nonlinear rational expectations commodity price model with unobservable state variables," Journal of Applied Econometrics, 10, S9-S40.

(1996): "Competitive Storage and Commodity Price Dynamics," Journal of Political Economy, 104(5), 896-923.

(2003): "A model of commodity prices after Sir Arthur Lewis," Journal of Development Economics, $71,289-310$.

Gardner, B. L. (1979): Optimal Stockpiling of Grain. Lexington Books, Lexington, Mass.

Goetzmann, W. N., and R. Ibbotson (2005): "History and the Equity Risk Premium," Yale ICF working paper No. 05.04.

Gourieraux, C., A. Monfort, and A. Trognon (1984): "Pseudo-Maximum Likelihood Methods: Theory," Econometrica, 52, 681-700.

Gustafson, R. L. (1958a): Carryover Levels for Grains. Washington D.C.: USDA, Technical bulletin 1178.

(1958b): "Implications of recent research on optimal storage rules," Journal of Farm Economics, $38,290-300$.

Hillman, J., D.G. Johnson and R. Gray (1975): "Food Reserve Policies for World Food Security." Food and Agriculture Organization of the United Nations, ESC/75/2., January 1975. 
Johnson, D. G., and D. Sumner (1976): "An Optimization Approach to Grain Reserves for Developing Countries," in Analysis of grain reserves: A Proceeding, ed. by D. J. Eaton, and W. S. Steele, pp. 56-76. U.S. Department of Agriculture, Economic Research Service Report No 634.

Michaelides, A., and S. Ng (2000): "Estimating the rational expectations model of speculative storage: A Monte Carlo comparison of three simulation estimators," Journal of Econometrics, 96, 231-266.

Miranda, M. J., and P. L. Fackler (2002): Applied Computational Economics and Finance. The MIT Press.

Miranda, M. J., and P. Helmberger (1988): "The effects of commodity price stabilization programs," American Economic Review, 78, 46-58.

Muth, J. F. (1961): "Rational Expectations and the Theory of Price Movement," Econometrica, 29(3), $315-335$.

Newbery, D. M. G., and J. E. Stiglitz (1979): "The Theory of Commodity Price Stabilization Rules: Welfare Impacts and Supply Responses," Economic Journal, 89, 799-817.

Newbery, D. M. G., and J. E. Stiglitz (1981) The Theory of Commodity Price Stabilization: A Study in the Economics of Risk, New York: Oxford University Press.

Park, A. (2006) "Risk and Household Grain Management in Developing Countries." Economic Journal, 116, 1088-1115.

Rees, A. (1961) Real Wages in Manufacturing, 1890-1914. (A Study by the National Bureau of Economic Research.) Princeton: Princeton University Press.

Samuelson, P. A. (1971): "Stochastic speculative price," Proceedings of the National Academy of Sciences, $68,335-337$.

UNCTAD (1975): "Second Progress Report on Storage Costs and Warehouse Facilities," TD/B/C.1/198, Trade and Development Board, Committee on Commodities, Geneva, United Nations Conference on Trade and Development.

Williams, J. C. (1986): The economic function of futures markets. Cambridge University Press, Cambridge, UK.

Williams, J. C., and B. D. Wright (1991): Storage and Commodity Markets. Cambridge: Cambridge University Press.

Working, H. (1929): "The post-harvest depression of wheat prices," Wheat studies of the Food Research Institute, 6, 1-40.

Wright, B. D., and J. C. Williams (1982): "The economic role of commodity storage," Economic Journal, 92, 596-614. 
Fig. 1. - Price characteristics implied by the storage model with linear inverse consumption demand $F(c)=600-50 c$ and production realizations drawn from a normal distribution with mean 100 and standard deviation 10, truncated at five standard deviations from the mean.
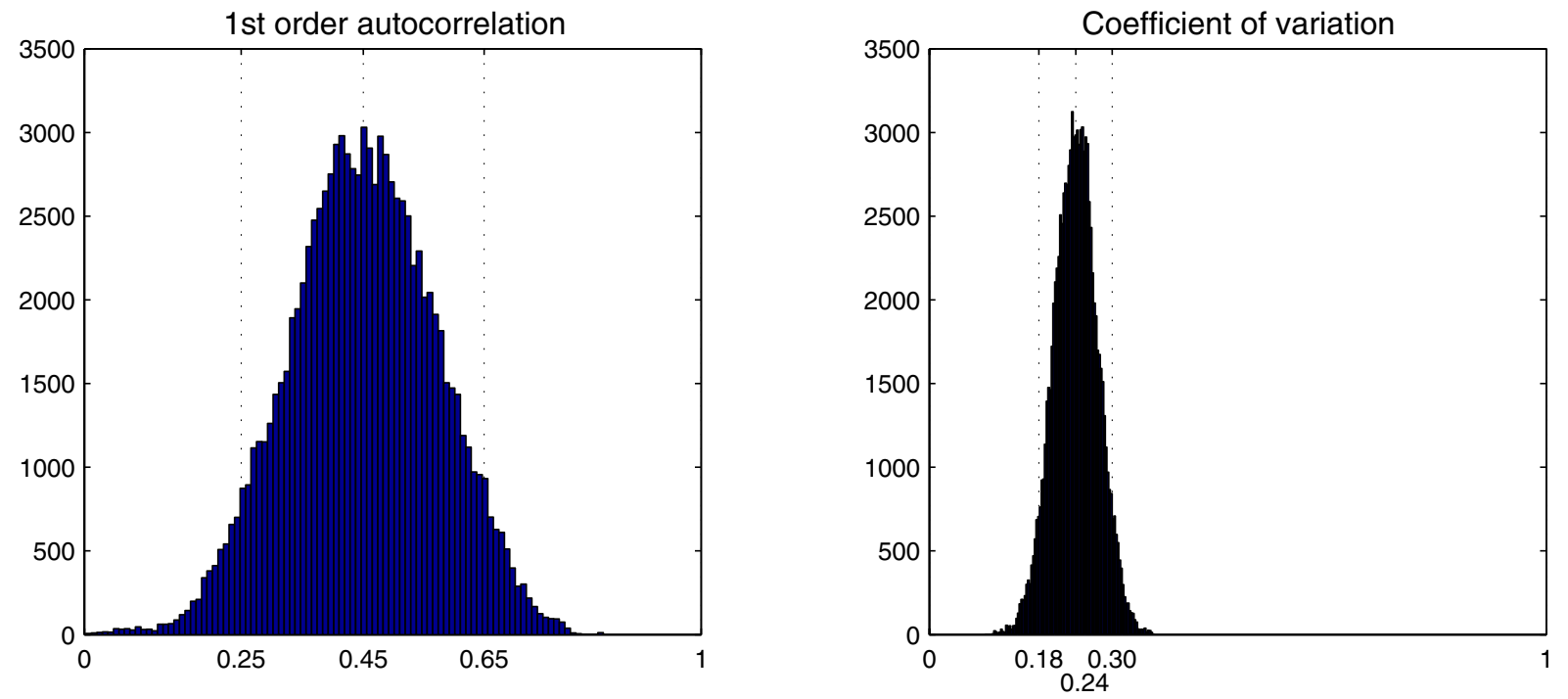

Note. - The numbers on the horizontal axes of the graphs report the values of the 5\%, 50\% and $95 \%$ percentiles. 
Fig. 2. - Price characteristics implied by the model with linear inverse consumption demand $F(c)=600-$ $150 \mathrm{c}$ and production realizations drawn from a normal distribution with mean 100 and standard deviation 10, truncated at five standard deviations from the mean.
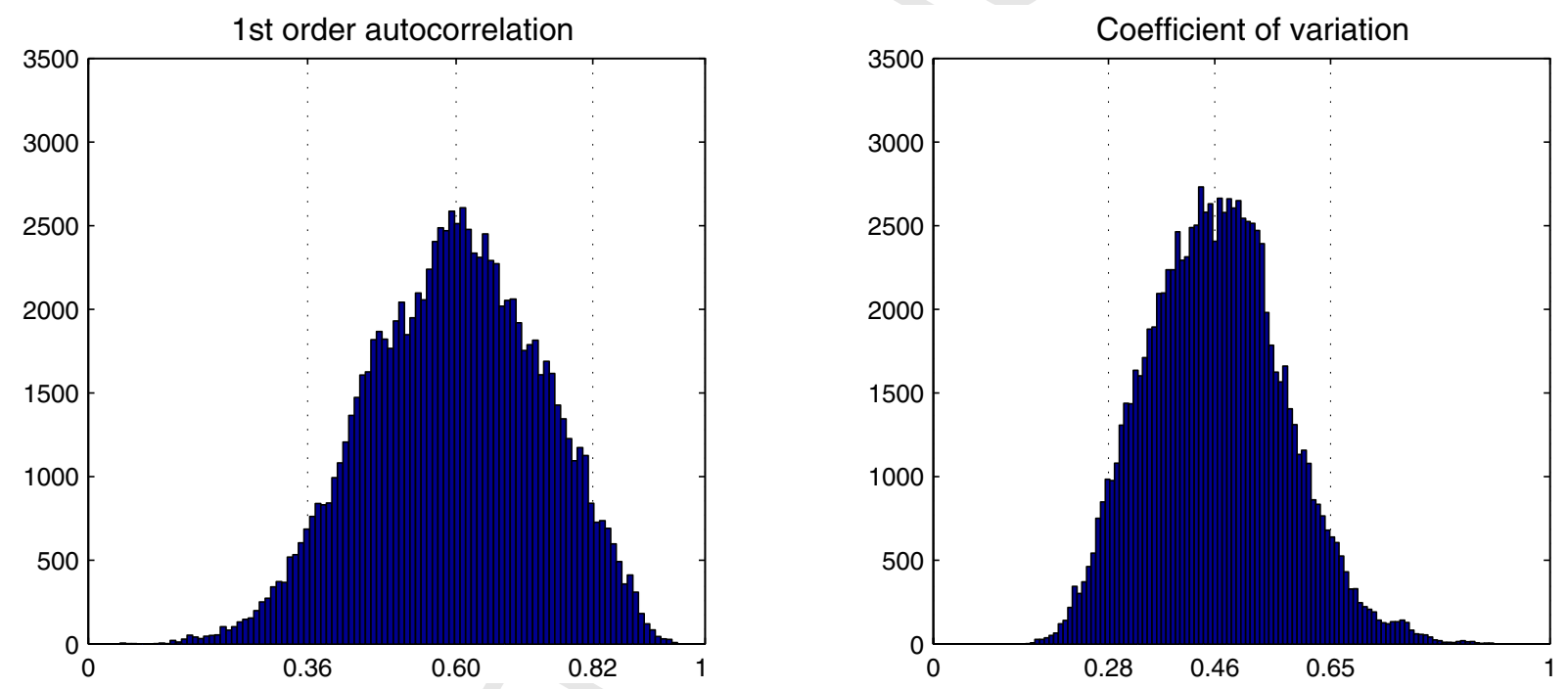

Note. - The numbers on the horizontal axes of the graphs report the values of the 5\%, 50\% and $95 \%$ percentiles. 
Fig. 3.- SUGAR: Implications of grid density for numerical approximation of the equilibrium price function

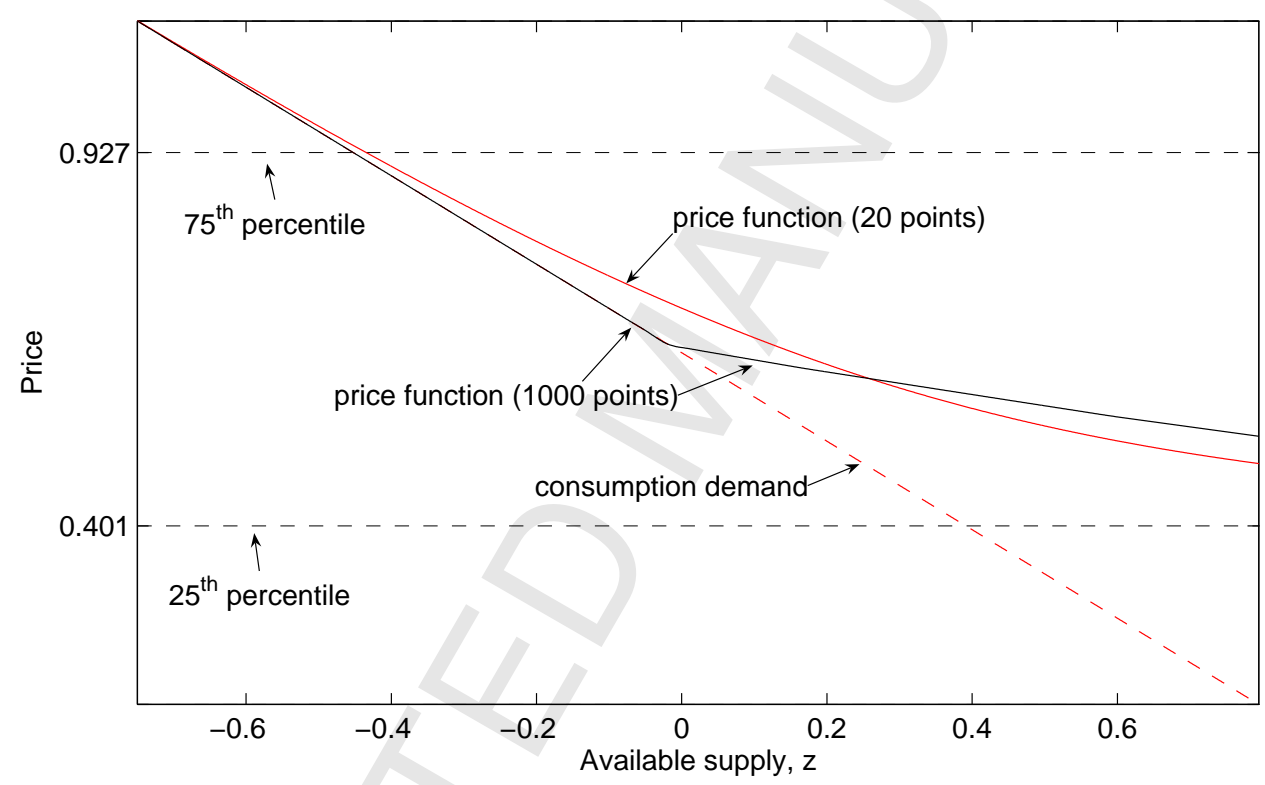

Note. - Both approximations assume the same linear consumption demand with parameters $a=0.645$, $b=-0.624$ and the same decay rate $d=0.179$. (These are the values obtained in our replication of Deaton and Laroque's estimate for sugar). The smoother price function is obtained with an approximation grid of 20 points, while the kinked price function is obtained with an approximation grid of 1000 points. The straight dashed line is the continuation of the assumed consumption demand function below the kink point. The horizontal dotted lines indicate the $25^{t h}$ and $75^{t h}$ percentiles of the sample prices for sugar. 
Fig. 4.- SUGAR: Dependence of estimation results on grid density

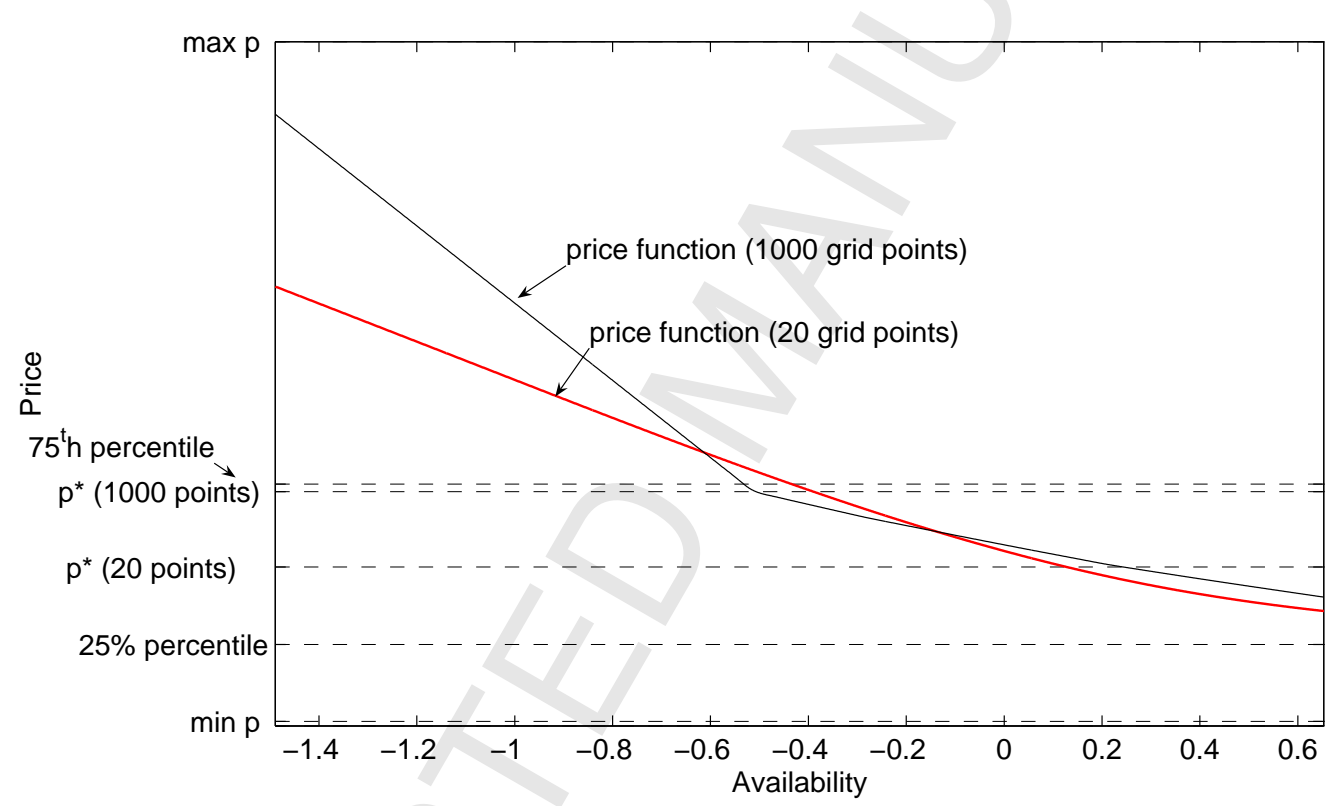

Note. - The functions are obtained by estimating the storage model for sugar, using the sparse grid of 20 points, and the fine grid of 1000 points, respectively. The horizontal dotted lines indicate the estimated "cut-off" prices $p^{*}$ for each case, and the $25^{\text {th }}$ and $75^{\text {th }}$ percentiles of the observed prices. Min $\mathrm{p}$ and max $\mathrm{p}$ indicate the minimum and maximum observed prices. 
$-18-$

Table 1. Variation and correlation in the commodity price time series (1900-1987)

\begin{tabular}{lccc}
\hline \hline Commodity & first order autocorrelation & second order autocorrelation & coefficient of variation \\
\hline bananas & 0.92 & 0.83 & 0.17 \\
cocoa & 0.84 & 0.66 & 0.54 \\
coffee & 0.81 & 0.61 & 0.45 \\
copper & 0.85 & 0.67 & 0.38 \\
cotton & 0.88 & 0.69 & 0.34 \\
jute & 0.71 & 0.45 & 0.33 \\
maize & 0.75 & 0.54 & 0.38 \\
palm oil & 0.72 & 0.48 & 0.48 \\
rice & 0.84 & 0.63 & 0.36 \\
sugar & 0.62 & 0.39 & 0.60 \\
tea & 0.80 & 0.64 & 0.26 \\
tin & 0.89 & 0.75 & 0.42 \\
wheat & 0.86 & 0.68 & 0.38 \\
\hline
\end{tabular}


Table 2. Our replication of the estimates of Deaton and Laroque $(1995,1996)$

\begin{tabular}{|c|c|c|c|c|}
\hline \multirow[b]{2}{*}{ Commodity } & \multicolumn{4}{|c|}{ Parameters $^{\mathrm{a}}$} \\
\hline & $a$ & $b$ & $d$ & $\mathrm{PL}$ \\
\hline \multirow[t]{2}{*}{ cocoa } & 0.1612 & -0.2190 & 0.1154 & 124.6209 \\
\hline & $(0.0022)$ & $(0.0069)$ & $(0.0086)$ & $\longrightarrow$ \\
\hline \multirow[t]{2}{*}{$\operatorname{cocoa}^{b}$} & 0.1412 & -0.2228 & 0.0550 & 129.9174 \\
\hline & $(0.0036)$ & $(0.0055)$ & $(0.0074)$ & \\
\hline \multirow[t]{2}{*}{ coffee } & 0.2620 & -0.1617 & 0.1360 & 112.0541 \\
\hline & $(0.0046)$ & $(0.0056)$ & $(0.0041)$ & \\
\hline \multirow[t]{2}{*}{ copper } & 0.5447 & -0.3268 & 0.0687 & 74.0137 \\
\hline & $(0.0074)$ & $(0.0114)$ & $(0.0040)$ & \\
\hline \multirow[t]{2}{*}{ cotton } & 0.6410 & -0.3131 & 0.1685 & 29.8815 \\
\hline & $(0.0072)$ & $(0.0073)$ & $(0.0060)$ & \\
\hline \multirow[t]{2}{*}{ jute } & 0.5681 & -0.3624 & 0.0933 & 45.2556 \\
\hline & $(0.0057)$ & $(0.0120)$ & $(0.0109)$ & \\
\hline \multirow[t]{2}{*}{ maize } & 0.58 & -0.962 & 0.0122 & 37.0061 \\
\hline & $(0.0100)$ & $(0.0330)$ & $(0.0069)$ & \\
\hline \multirow[t]{2}{*}{ palm oil } & 0.4618 & -0.4288 & 0.0579 & 22.1912 \\
\hline & $(0.0109)$ & $(0.0128)$ & $(0.0060)$ & \\
\hline \multirow[t]{2}{*}{ rice } & 0.5979 & -0.3358 & 0.1471 & 26.0648 \\
\hline & $(0.0056)$ & $(0.0063)$ & $(0.0083)$ & \\
\hline \multirow[t]{2}{*}{ sugar } & 0.6451 & -0.6240 & 0.1790 & -10.7309 \\
\hline & $(0.0100)$ & $(0.0140)$ & $(0.0066)$ & \\
\hline \multirow[t]{2}{*}{ tea } & 0.4762 & -0.2156 & 0.1190 & 69.6786 \\
\hline & $(0.0037)$ & $(0.0054)$ & $(0.0070)$ & \\
\hline \multirow[t]{2}{*}{$\operatorname{tin}$} & 0.2531 & -0.1728 & 0.1441 & 110.1603 \\
\hline & $(0.0092)$ & $(0.0103)$ & $(0.0110)$ & \\
\hline \multirow[t]{2}{*}{ wheat } & 0.6358 & -0.4236 & 0.0575 & 28.5261 \\
\hline & $(0.0081)$ & $(0.0069)$ & $(0.0051)$ & \\
\hline \multirow[t]{2}{*}{ wheat $^{c}$} & 1.0711 & -1.0403 & 0.0936 & 10.5416 \\
\hline & $(0.0237)$ & $(0.1067)$ & $(0.0152)$ & \\
\hline
\end{tabular}

asymptotic standard errors in parentheses. PL is the values of the maximized log Pseudo-Likelihood.

${ }^{\mathrm{b}}$ Estimates for a grid of 20 points.

${ }^{c}$ Estimates for a lower limit of the grid of -3 .

Note. - For all commodities but cocoa and wheat, we use the same grid limits and sizes of Deaton and Laroque 
(1995, Table I). For cocoa, we replicate Deaton and Laroque's estimates with 21 grid points. instead of 20 and for wheat the lower limit is set at -5 rather than -3 . 
Table 3. Estimation of Deaton and Laroque models for varying grid size

\begin{tabular}{ccccc}
\hline \hline Grid size & $a$ & $b$ & $d$ & PL \\
\hline \multicolumn{5}{c}{ COTTON } \\
10 & 0.6410 & -0.3131 & 0.1685 & 29.8815 \\
19 & 0.6343 & -0.3281 & 0.1515 & 28.3221 \\
37 & 0.6219 & -0.3560 & 0.1254 & 28.4064 \\
73 & 0.5716 & -0.4366 & 0.0805 & 29.5948 \\
145 & 0.5301 & -0.5191 & 0.0462 & 29.6861 \\
577 & 0.5292 & -0.5123 & 0.0478 & 29.6761 \\
1000 & 0.5295 & -0.5133 & 0.0478 & 29.6761 \\
1153 & 0.5311 & -0.5114 & 0.0485 & 29.6783 \\
& & SUGAR & & \\
10 & 0.6451 & -0.6240 & 0.1790 & -10.73 \\
19 & 0.2296 & -1.2345 & 0.0000 & -6.745 \\
37 & 0.3875 & -1.1687 & 0.0540 & -7.753 \\
73 & 0.2436 & -1.2615 & 0.0000 & -6.815 \\
145 & 0.2514 & -1.2742 & 0.0003 & -6.788 \\
577 & 0.2535 & -1.2650 & 0.0016 & -6.791 \\
1000 & 0.2543 & -1.2661 & 0.0020 & -6.785 \\
1217 & 0.2579 & -1.2628 & 0.0043 & -6.819 \\
1500 & 0.2552 & -1.2648 & 0.0022 & -6.785 \\
\hline & & & &
\end{tabular}

Note. - Other than for the 1000 points, from one step to the next, the number of grid points have been changed to increase the number of grid nodes without affecting the position of the existing ones, to avoid introducing further instabilities in the pseudo likelihood maximization routine. The previous estimates are used as starting values for the estimates using the next grid size. 
$-22-$

Table 4. Estimation of the Deaton and Laroque model with fine grids of 1000 points

\begin{tabular}{lcccc}
\hline \hline Commodity & $a$ & $b$ & $d$ & $\mathrm{PL}$ \\
\hline cocoa & 0.1276 & -0.2651 & 0.0520 & 118.814 \\
coffee & 0.6804 & -6.4599 & 0.0 & 131.722 \\
copper & 1.0482 & -2.9135 & 0.0 & 96.798 \\
cotton & 0.5295 & -0.5133 & 0.0478 & 29.676 \\
jute & 0.5572 & -0.5738 & 0.0360 & 38.599 \\
maize & 1.3842 & -6.4838 & 0.0 & 41.425 \\
palm oil & 1.0975 & -5.5795 & 0.0 & 65.155 \\
sugar & 0.2545 & -1.2656 & 0.0020 & -6.79 \\
tea & 0.5108 & -0.1687 & 0.1554 & 63.865 \\
\hline
\end{tabular}


$-23-$

Table 5. Grids used in the estimation

\begin{tabular}{lccc}
\hline \hline Commodity & minimum $z$ & maximum $z$ & points \\
\hline coffee & -5 & 30 & 1000 \\
copper & -5 & 40 & 1000 \\
jute & -5 & 30 & 1000 \\
maize & -5 & 40 & 1000 \\
palm oil & -5 & 30 & 1000 \\
sugar & -5 & 20 & 1000 \\
tin & -5 & 45 & 1000 \\
\hline
\end{tabular}


Table 6. Estimation of the constant marginal storage cost model $(r=0.05)$

\begin{tabular}{|c|c|c|c|c|c|}
\hline \multirow[b]{2}{*}{ Commodity } & \multicolumn{4}{|c|}{ Parameters } & \multirow[b]{2}{*}{$p^{*}$} \\
\hline & $a$ & $b$ & $k$ & $\overline{P L}$ & \\
\hline coffee & $\begin{array}{c}0.5595 \\
(0.0254)\end{array}$ & $\begin{array}{l}-3.0740 \\
(0.1897)\end{array}$ & $\begin{array}{c}0.0014 \\
(0.0004)\end{array}$ & 131.8995 & 2.1443 \\
\hline copper & $\begin{array}{c}0.9952 \\
(0.0244)\end{array}$ & $\begin{array}{l}-2.4775 \\
(0.1487)\end{array}$ & $\begin{array}{c}0.0008 \\
(0.0006)\end{array}$ & 96.8285 & 2.1775 \\
\hline jute & $\begin{array}{c}1.1786 \\
(0.0402)\end{array}$ & $\begin{array}{l}-3.5997 \\
(0.1217)\end{array}$ & $\begin{array}{c}0.0064 \\
(0.0016)\end{array}$ & 53.5848 & 2.9230 \\
\hline maize & $\begin{array}{c}1.1395 \\
(0.0263)\end{array}$ & $\begin{array}{l}-2.3857 \\
(0.0799)\end{array}$ & $\begin{array}{c}0.0096 \\
(0.0015)\end{array}$ & 41.4971 & 2.2195 \\
\hline palm oil & $\begin{array}{c}1.2535 \\
(0.0279)\end{array}$ & $\begin{array}{l}-4.1106 \\
(0.0933)\end{array}$ & $\begin{array}{c}0.0053 \\
(0.0007)\end{array}$ & 66.0275 & 3.2682 \\
\hline sugar & $\begin{array}{c}0.6052 \\
(0.0206)\end{array}$ & $\begin{array}{l}-0.8841 \\
(0.0236)\end{array}$ & $\begin{array}{c}0.0329 \\
(0.0042)\end{array}$ & -2.4624 & 0.9020 \\
\hline $\operatorname{tin}^{a}$ & $\begin{array}{c}5.8695 \\
(0.0420)\end{array}$ & $\begin{array}{r}-24.1231 \\
(1.2814)\end{array}$ & $\begin{array}{c}0.0024 \\
(0.0004)\end{array}$ & 152.4536 & 18.0644 \\
\hline
\end{tabular}

aThe estimate reported for tin is one of several that generate the same value of the maximized pseudo likelihood.

Note. - Asymptotic standard errors in parentheses. 
Table 7. Estimation of the constant marginal storage cost model $(r=0.02)$

\begin{tabular}{|c|c|c|c|c|c|}
\hline \multirow[b]{2}{*}{ Commodity } & \multicolumn{4}{|c|}{ Parameters } & \multirow[b]{2}{*}{$p^{*}$} \\
\hline & $a$ & $b$ & $k$ & $\mathrm{PL}$ & \\
\hline coffee & $\begin{array}{c}0.3047 \\
(0.0220)\end{array}$ & $\begin{array}{l}-1.8866 \\
(0.0946)\end{array}$ & $\begin{array}{c}0.0035 \\
(0.0005)\end{array}$ & 132.6319 & 1.3657 \\
\hline copper & $\begin{array}{c}0.6787 \\
(0.0171)\end{array}$ & $\begin{array}{l}-1.9770 \\
(0.0724)\end{array}$ & $\begin{array}{c}0.0053 \\
(0.0006)\end{array}$ & 99.8395 & 1.7463 \\
\hline jute & $\begin{array}{c}0.8615 \\
(0.0491)\end{array}$ & $\begin{array}{l}-3.2399 \\
(0.1523)\end{array}$ & $\begin{array}{c}0.0115 \\
(0.0018)\end{array}$ & 55.3096 & 2.6210 \\
\hline maize & $\begin{array}{c}0.9217 \\
(0.0428)\end{array}$ & $\begin{array}{l}-2.8352 \\
(0.1203)\end{array}$ & $\begin{array}{c}0.0129 \\
(0.0018)\end{array}$ & 43.7939 & 2.4331 \\
\hline palm oil & $\begin{array}{c}0.8427 \\
(0.0277)\end{array}$ & $\begin{array}{l}-3.2298 \\
(0.1025)\end{array}$ & $\begin{array}{c}0.0099 \\
(0.0009)\end{array}$ & 68.8829 & 2.6042 \\
\hline sugar & $\begin{array}{c}0.5829 \\
(0.0356)\end{array}$ & $\begin{array}{l}-0.8769 \\
(0.0275)\end{array}$ & $\begin{array}{c}0.0429 \\
(0.0067)\end{array}$ & -2.7104 & 0.9051 \\
\hline $\operatorname{tin}$ & $\begin{array}{c}0.5741 \\
(0.0038)\end{array}$ & $\begin{array}{l}-2.6174 \\
(0.0105)\end{array}$ & $\begin{array}{c}0.0039 \\
(0.0001)\end{array}$ & 155.6304 & 2.0351 \\
\hline
\end{tabular}

Note. - Asymptotic standard errors in parentheses. 
Table 8. Maximized Log Pseudo-Likelihood Values for various models

\begin{tabular}{|c|c|c|c|c|c|}
\hline & \multirow{2}{*}{$\begin{array}{l}\text { proportional decay }^{\mathrm{a}} \\
\text { sparse grid }\end{array}$} & \multirow{2}{*}{$\begin{array}{l}\text { proportional decay } \\
\text { dense grid } 1000 \text { pts. }\end{array}$} & \multirow{2}{*}{$\operatorname{AR}(1)^{c}$} & \multicolumn{2}{|c|}{ fixed marginal cost $\mathrm{t}^{\mathrm{d}}$} \\
\hline & & & & $r=0.05$ & $r=0.02$ \\
\hline cocoa & 125.2 & 118.8 & 124.1 & - & - \\
\hline coffee & 111.0 & 131.7 & 118.9 & 131.9 & 132.6 \\
\hline copper & 73.9 & 96.8 & 81.1 & 96.8 & 99.8 \\
\hline cotton & 29.8 & 29.7 & 74.2 & - & - \\
\hline jute & 44.8 & 38.6 & 50.2 & 53.5 & 55.3 \\
\hline maize & 32.1 & $41.4 \quad$ & 27.0 & 41.5 & 43.8 \\
\hline palm oil & 22.2 & 65.1 & 27.6 & 65.9 & 68.9 \\
\hline rice & 26.0 & - & 61.0 & - & - \\
\hline sugar & -10.7 & -6.8 & -27.0 & -2.5 & -2.7 \\
\hline tea & 69.3 & 63.9 & 100.9 & - & - \\
\hline $\operatorname{tin}$ & 108.9 & - & 150.9 & 152.4 & 155.6 \\
\hline wheat & 24.6 & - & 52.8 & - & - \\
\hline
\end{tabular}

${ }^{a}$ Model estimated by Deaton and Laroque $(1995,1996)$, values reported in Deaton and Laroque (1995, Table III, column 3).

${ }^{\mathrm{b}}$ Deaton and Laroque specification estimated with a fine grid of 1000 points.

${ }^{\mathrm{c}}$ Reported by Deaton and Laroque (1995, Table III, column 2).

${ }^{\mathrm{d}}$ Specifications used by Gustafson (1958a), estimated with a dense grid of 1000 points. 
Table 9. Characteristics of price series and model predictions

\begin{tabular}{|c|c|c|c|c|}
\hline Commodity/Model & mean & a.c. 1 & a.c. 2 & $\mathrm{CV}$ \\
\hline \multicolumn{5}{|l|}{ Cocoa } \\
\hline Observed values & 0.1971 & \multicolumn{2}{|c|}{$0.8357 \quad 0.6618$} & 0.5444 \\
\hline \multicolumn{5}{|l|}{ Percentiles } \\
\hline Proportional decay, sparse grid & 69.15 & 100 & 100 & 77.26 \\
\hline Proportional decay, dense grid, $r=5 \%$ & 97.7 & 99.94 & 99.49 & 28.15 \\
\hline Constant marginal storage cost, dense grid, $r=5 \%$ & n.a. & n.a. & n.a. & n.a. \\
\hline Constant marginal storage cost, dense grid, $r=2 \%$ & n.a. & n.a. & n.a. & n.a. \\
\hline \multicolumn{5}{|l|}{ Coffee } \\
\hline Observed values & 0.226 & 0.8058 & 0.6146 & 0.4524 \\
\hline \multicolumn{5}{|l|}{ Percentiles } \\
\hline Proportional decay, sparse grid & 0.12 & 100 & 100 & 99.5 \\
\hline Proportional decay, dense grid, $r=5 \%$ & 20.42 & 44.12 & 33.45 & 4.32 \\
\hline Constant marginal storage cost, dense grid, $r=5 \%$ & 12.31 & 59.61 & 47.51 & 4.55 \\
\hline Constant marginal storage cost, dense grid, $r=2 \%$ & 33.75 & 42.9 & 32.48 & 7.33 \\
\hline \multicolumn{5}{|l|}{ Copper } \\
\hline Observed values & 0.4912 & 0.8514 & 0.6615 & 0.3802 \\
\hline \multicolumn{5}{|l|}{ Percentiles } \\
\hline Proportional decay, sparse grid & 1.53 & 100 & 100 & 97.73 \\
\hline Proportional decay, dense grid, $r=5 \%$ & 2.65 & 88.67 & 75.43 & 8.06 \\
\hline Constant marginal storage cost, dense grid, $r=5 \%$ & 2.07 & 91.11 & 79.21 & 9.45 \\
\hline Constant marginal storage cost, dense grid, $r=2 \%$ & 16.92 & 75.2 & 57.66 & 22.24 \\
\hline \multicolumn{5}{|l|}{ Cotton } \\
\hline Observed values & 0.6463 & 0.8842 & 0.6808 & 0.3464 \\
\hline \multicolumn{5}{|l|}{ Percentiles } \\
\hline Proportional decay, sparse grid & 38.21 & 100 & 100 & 64.06 \\
\hline Proportional decay, dense grid, $r=5 \%$ & 96.62 & 100 & 100 & 10.73 \\
\hline Constant marginal storage cost, dense grid, $r=5 \%$ & n.a. & n.a. & n.a. & n.a. \\
\hline Constant marginal storage cost, dense grid, $r=2 \%$ & n.a. & n.a. & n.a. & n.a. \\
\hline \multicolumn{5}{|l|}{ Jute } \\
\hline Observed values & 0.5994 & 0.7057 & 0.4549 & 0.325 \\
\hline \multicolumn{5}{|l|}{ Percentiles } \\
\hline Proportional decay, sparse grid & 59.83 & 100 & 100 & 47.84 \\
\hline Proportional decay, dense grid, $r=5 \%$ & 62.92 & 98.82 & 91.57 & 7.14 \\
\hline Constant marginal storage cost, dense grid, $r=5 \%$ & 5.79 & 56.83 & 35.78 & 0.84 \\
\hline Constant marginal storage cost, dense grid, $r=2 \%$ & 20.75 & 35.2 & 20.02 & 1.86 \\
\hline \multicolumn{5}{|l|}{ Maize } \\
\hline Observed values & 0.7141 & 0.753 & 0.526 & 0.3834 \\
\hline \multicolumn{5}{|l|}{ Percentiles } \\
\hline Proportional decay, sparse grid & 86.83 & 65.78 & 46.86 & 27.54 \\
\hline Proportional decay, dense grid, $r=5 \%$ & 14.59 & 49.77 & 35.52 & 3.43 \\
\hline Constant marginal storage cost, dense grid, $r=5 \%$ & 4.52 & 81.47 & 63.95 & 6.71 \\
\hline Constant marginal storage cost, dense grid, $r=2 \%$ & 23.91 & 51.77 & 35.66 & 9.96 \\
\hline
\end{tabular}


Table 9-Continued

\begin{tabular}{|c|c|c|c|c|}
\hline Commodity/Model & mean & a.c. 1 & a.c. 2 & $\mathrm{CV}$ \\
\hline \multicolumn{5}{|l|}{ Palmoil } \\
\hline Observed values & 0.5425 & 0.7246 & 0.4723 & 0.4772 \\
\hline \multicolumn{5}{|l|}{ Percentiles } \\
\hline Proportional decay, sparse grid & 91.58 & 100 & 98.74 & 70.3 \\
\hline Proportional decay, dense grid, $r=5 \%$ & 15.4 & 41.84 & 25.95 & 11.3 \\
\hline Constant marginal storage cost, dense grid, & 3.37 & 68.06 & 45.43 & 16.32 \\
\hline Constant marginal storage cost, dense grid, & 16.84 & 36.81 & 21.2 & 22.96 \\
\hline \multicolumn{5}{|l|}{ Sugar } \\
\hline Observed value & 0.7096 & 0.6202 & 0.3836 & 0.6037 \\
\hline \multicolumn{5}{|l|}{ Percentiles } \\
\hline Proportional decay, sparse grid & 62.28 & 100 & 100 & 82.23 \\
\hline Proportional decay, dense grid, $r=5 \%$ & 100 & 29.85 & 17.59 & 29.98 \\
\hline Constant marginal storage cost, dense grid, $r=5 \%$ & 87.67 & 84.06 & 67.48 & 44.27 \\
\hline Constant marginal storage cost, dense grid, $r=2 \%$ & 92.05 & 80.8 & 63.61 & 42.5 \\
\hline \multicolumn{5}{|l|}{ Tea } \\
\hline Observed values & 0.5133 & 0.7989 & 0.6161 & 0.257 \\
\hline \multicolumn{5}{|l|}{ Percentiles } \\
\hline Proportional decay, sparse grid & 88.46 & 100 & 100 & 29.44 \\
\hline Proportional decay, dense grid, $r=5 \%$ & 45.46 & 100 & 100 & 40.32 \\
\hline Constant marginal storage cost, dense grid, $r=5 \%$ & n.a. & n.a. & n.a. & n.a. \\
\hline Constant marginal storage cost, dense grid, $r=2 \%$ & n.a. & n.a. & n.a. & n.a. \\
\hline \multicolumn{5}{|l|}{ Tin } \\
\hline Observed values & 0.2221 & 0.8859 & 0.7554 & 0.415 \\
\hline \multicolumn{5}{|l|}{ Percentiles } \\
\hline Proportional decay, sparse grid & 0.44 & 100 & 100 & 79.2 \\
\hline ecay, dense grid, $r=5 \%$ & n.a. & n.a. & n.a. & n.a. \\
\hline prage cost, dense grid, $r=5 \%$ & 0 & 88.02 & 81.64 & 6.49 \\
\hline Constant marginal storage cost, dense grid, $r=2 \%$ & 6.93 & 74.75 & 65.15 & 17.48 \\
\hline \multicolumn{5}{|l|}{ Wheat } \\
\hline Observed values & 0.69 & 0.86 & 0.68 & 0.38 \\
\hline \multicolumn{5}{|l|}{ Percentiles } \\
\hline Proportional decay, sparse grid & 80.45 & 100 & 100 & 79.91 \\
\hline Proportional decay, dense grid, $r=5 \%$ & n.a. & n.a. & n.a. & n.a. \\
\hline Constant marginal storage cost, $r=5 \%$ & n.a. & n.a. & n.a. & n.a. \\
\hline Constant marginal storage cost, $r=2 \%$ & n.a. & n.a. & n.a. & n.a. \\
\hline
\end{tabular}


Table 10. Implied probability of at least $n$ stockout in periods of 88 years

\begin{tabular}{|c|c|c|c|c|c|c|c|c|c|}
\hline & \multicolumn{9}{|c|}{ Model } \\
\hline & \multirow{3}{*}{\multicolumn{3}{|c|}{$\begin{array}{c}\text { proportional decay }{ }^{\mathrm{a}} \\
(r=5 \%) \\
n\end{array}$}} & \multicolumn{6}{|c|}{ constant marginal cost ${ }^{\mathrm{b}}$} \\
\hline & & & & \multirow{2}{*}{\multicolumn{3}{|c|}{$\begin{array}{c}(r=5 \%) \\
n\end{array}$}} & \multirow{2}{*}{\multicolumn{3}{|c|}{$\begin{array}{c}(r=2 \%) \\
n\end{array}$}} \\
\hline & & & & & & & & & \\
\hline & 1 & 5 & 10 & 1 & 5 & 10 & 1 & 5 & 10 \\
\hline Cocoa & 0.9917 & 0.8252 & 0.3909 & n.a. & n.a. & n.a. & n.a. & n.a. & n.a. \\
\hline Coffee & 0.3315 & 0.0574 & 0.0030 & 0.5219 & 0.1213 & 0.0097 & 0.3683 & 0.0542 & 0.0030 \\
\hline Copper & 0.7435 & 0.2603 & 0.0362 & 0.7835 & 0.2973 & 0.0464 & 0.5656 & 0.1219 & 0.0100 \\
\hline Cotton & 0.9999 & 0.9802 & 0.8165 & n.a. & n.a. & n.a. & n.a. & n.a. & n.a. \\
\hline Jute & 0.9986 & 0.9539 & 0.6915 & 0.7463 & 0.2585 & 0.0359 & 0.5491 & 0.1083 & 0.0092 \\
\hline Maize & 0.5589 & 0.1346 & 0.0127 & 0.8859 & 0.4252 & 0.0958 & 0.6322 & 0.1450 & 0.0130 \\
\hline Palm oil & 0.5286 & 0.1241 & 0.0109 & 0.7183 & 0.2307 & 0.0310 & 0.5289 & 0.0989 & 0.0088 \\
\hline Sugar & 0.6137 & 0.1455 & 0.0145 & 0.9963 & 0.9044 & 0.5518 & 0.9939 & 0.8649 & 0.4633 \\
\hline Tea & 1.0000 & 1.0000 & 1.0000 & n.a. & n.a. & n.a. & n.a. & n.a. & n.a. \\
\hline Tin & 0.4294 & 0.0919 & 0.0070 & 0.6069 & 0.1575 & 0.0165 & 0.4056 & 0.0639 & 0.0041 \\
\hline
\end{tabular}

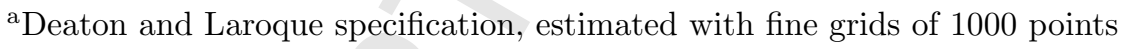

${ }^{\mathrm{b}}$ Specifications proposed by Gustafson, estimated with fine grids of 1000 points. 
Table 11. Average profits

\begin{tabular}{lccccccc}
\hline \hline & \multicolumn{7}{c}{ Commodity } \\
\cline { 2 - 8 } & Coffee & Copper & Jute & Maize & Palm oil & Sugar & Tin \\
\hline$r=0.05$ & & & & & & & \\
$\quad \begin{array}{l}\text { average profits } \\
\text { percentiles }\end{array}$ & -0.0123 & -0.0302 & -0.0381 & -0.0489 & -0.0389 & -0.0122 & -0.0130 \\
$r=0.02$ & 54.2 & 39.9 & 39.6 & 22.7 & 42.5 & 69.6 & 73.2 \\
$\quad \begin{array}{l}\text { average profits } \\
\text { percentiles }\end{array}$ & -0.0081 & -0.0210 & -0.0265 & -0.0321 & -0.0262 & -0.0054 & -0.0083 \\
\hline
\end{tabular}

Note. - The table reports the results for the constant marginal storage cost model, estimated for the two alternate interest rate values. For each model, average profits implied by the estimated models evaluated on the actual 88 year price series are reported in the first row. Percentiles of the corresponding distribution of average profits over 88-periods samples taken from one long series of 100,000 prices are reported in the second row. 